\title{
Contribuiçóes para a Fisioterapia a Partir dos Pontos de Vista das Crianças ${ }^{1}$ Contributions for Physical Therapy from the Children's Point of View
}

\author{
Kadine Priscila Bender dos SANTOS ${ }^{2}$ \\ Valéria Silva FERREIRA ${ }^{3}$
}

\begin{abstract}
RESUMO: este relato de pesquisa teve como objetivo ouvir o que as crianças dizem sobre a fisioterapia. A pesquisa contou com a participaçáo de sete crianças com doenças crônicas que faziam fisioterapia por tempo indeterminado, em um hospital e em um centro de fisioterapia. Essas crianças foram entrevistadas a partir de questionamentos relativos à doença, ao tratamento e sobre brincar durante a fisioterapia. Propôs-se pesquisar com as crianças e não sobre elas, tendo em vista que a infância é uma categoria social e que as doenças crônicas sugerem mais atenção quanto à qualidade de vida infantil. Este estudo demonstra a possibilidade de uma aproximação efetiva com a educação, por meio da Sociologia da Infância, e da Saúde no âmbito de humanizar a relação entre fisioterapeuta e criança. Com os resultados, foi possível identificar que essas crianças relacionam a doença ao problema e à melhora, traduzindo a trajetória que a doença impốe em suas vidas. A doença é a geradora da hospitalização e do motivo de realizarem a fisioterapia, que é considerada o tratamento que atua no seu problema e objetiva sua melhora. As crianças deixam claro que querem brincar mais, sendo, assim, o planejar do brincar terapêutico nas clínicas e hospitais necessário. Conclui-se, portanto, que é indispensável incluir a terapia lúdica, para que brincar na fisioterapia seja prazeroso, estimulante, na tentativa de objetivar o brincar terapêutico. Esse é o desafio. Por esse viés, pode-se dizer que reabilitar, também, requer conhecimento pedagógico.
\end{abstract}

PALAVRAS-CHAVE: Educação Especial. Fisioterapia. Infância. Terapia lúdica. Humanização.

\begin{abstract}
The aim of this research report was to listen to what children have to say about physiotherapy. Seven children with chronic diseases, who were being seen in physiotherapy in a hospital and a physiotherapy center for an indefinite period, participated in the study. These children were interviewed, and the questions related to their disease, treatment and play during physiotherapy. The study was designed from the children's point of view rather than being about them. Childhood is understood as a social category and chronic diseases require more concern for children's quality of life. This study demonstrates the possibility of bringing together education, through Sociology of Childhood, and Health, as an effort to humanize the relationship between therapist and child. The results showed that these children relate their diseases to the problem and to their improvement, and they are able to interpret the trajectory that the disease imposes on their lives. Disease is the generator of hospitalization and the reason they must do physiotherapy, which is understood as the treatment that acts upon their problem, in order to promote their improvement. Children clearly report that they want to play more, indicating the importance of planning therapeutic play in clinics and hospitals. We conclude that including recreational therapy is essential, in order for play in physiotherapy to be pleasant, stimulating, aiming for therapeutic play. That is the challenge. From this approach, it can be stated that rehabilitation also requires educational knowledge.
\end{abstract}

KEYWORDS: Special Education. Physiotherapy. Childhood. Recreational therapy. Humanization.

\section{INTRODUÇÃo}

As crianças, muitas vezes, utilizam as palavras "como" ou "porquê" na tentativa de compreender o mundo. Sendo assim, a fim de um atendimento sob a ótica da integralidade para a fisioterapia pediátrica, que considera a potencialidade das crianças, tanto física, emocional e,

\footnotetext{
${ }^{1}$ Esta pesquisa teve apoio financeiro da Coordenaçáo de aperfeiçoamento de Pessoal de Nível Superior (Capes).

${ }^{2}$ Fisioterapeuta, Mestre em Educação (UNIVALI/SC). kadinebender@hotmail.com

${ }^{3}$ Doutora em Psicologia da Educação (PUC/SP). Mestre em Educação (UFPR/PR). v.ferreira@univali.br
} 
sobretudo, intelectual, aos fisioterapeutas, interessados na criança, propóe-se refletir sobre a fisioterapia na infância.

Esta pesquisa interessa-se sobre a infância das crianças doentes e deficientes que convivem com a doença crônica e com a fisioterapia e propóe compreender a infância como categoria social, pois, segundo Sarmento:

Os estudos da infância são, nas suas dimensões interdisciplinares, um campo de estudo em pleno progresso e desenvolvimento. A partir do olhar da sociologia, da história, da antropologia, da psicologia, etc., e tomado por foco a infância como categoria social do tipo geracional, têmse vindo a desenvolver trabalhos de pesquisa que procuram resgatar a infância como objeto de conhecimento, nas suas múltiplas articulaçóes como as diversas esferas, categorias e estruturas da sociedade. (SARMENTO, 2009, p. 9).

Para fazer um eixo entre educação (Sociologia da Infância) e Saúde, é fundamental compreender que as crianças começaram a ser estudadas por meio das ciências médicas, mas dentro de uma visão que as quantificava - o que ainda perdura -, sendo as crianças analisadas dentro de uma ideia de normalidade, assim investigando-se seu desenvolvimento - crítica feita, também, por Vygotsky no seu estudo Defectologia ${ }^{4}$, já que a criança é vista pelo pensador como "um tipo de desenvolvimento especial e não como uma variável quantitativa do normal". (VYGOTSKY, $1997^{5}$, p. 13).

A Sociologia da Infância surge pensar na criança como cidadã, aquela que é intergeracional, pois ela convive com os irmãos, pais e avós. Também são urbanas, pois vão às praças, às escolas; caminham pelas cidades, traduzindo justiça, economia, desigualdade; transformando o mundo. A Sociologia da Infância vem para problematizar a abordagem psicológica e biológica no que se refere à criança e discutir estes saberes que pertencem à Psicologia e à Medicina (1980), as quais tinham o foco no adulto (ABRAMOWICZ; OLIVEIRA, 2010).

As vozes das crianças deficientes têm sido raramente ouvidas em investigaçóes ou emergem apenas em estudos preocupados com problemas de assistência ou caracterizados por narrativas de dependência, de vulnerabilidade e de exclusão, descrevendo-as como um grupo homogêneo, estabelecendo um elo entre a deficiência e a pobreza (BURLEY; DAVIS; WATSON, 2005).

Acreditando na importância da fisioterapia no processo de humanização da saúde, este estudo compreende que, quando o fisioterapeuta tem como objetivo proporcionar qualidade de vida para seu paciente pediátrico, ele deveria considerar, primeiramente, suas falas, pois, dessa forma, ele poderia refletir a qualidade na infância.

A criança incorpora os tempos presente, passado e futuro, ela renova oportunidades, o que é próprio da sua capacidade de transpor espaço e tempo e de relacionar o real com o imaginário. (SARMENTO, 2005). Pensar na qualidade de vida infantil é incluí-la, é ouvi-la, é pensar não somente no seu futuro, pois, se o tempo dela é o presente, então ela também

\footnotetext{
${ }^{4}$ Defectologia - ciência que na visão Vygotskyana considera que todo defeito é gerador de estímulos para elaboraçâo da compensaçấo. Vygotsky estudou a Defectologia não somente quantificando o desenvolvimento infantil, mas também investigou qualitativamente as crianças deficientes.

${ }^{5}$ Este ensaio foi escrito em 1983.
} 
é contemporânea. A Sociologia da Infância vem proclamar metodologias que estabeleçam conexão com os "devires"' das crianças, as quais, em alguns momentos, geram fraturas, rompem com o que para os adultos é natural e necessário. (ABRAMOWICZ; OLIVEIRA, 2010).

Percebe-se que, com a evolução dos conhecimentos técnicos utilizados no atendimento pediátrico, ocorre a diminuição da morbidez e da mortalidade infantil, mas isso não significa que hoje esses pacientes possuam qualidade de vida infantil, principalmente quando se pensa naquelas que ficaram com alguma deficiência e que necessitarão de fisioterapia por tempo indeterminado.

Conversar mais durante a reabilitação com esses pacientes é importante e necessário para questionar-se quanto aos conhecimentos pessoais e acadêmicos sobre a infância, para, assim, compreender o que é prioridade a partir de suas falas sobre qualidade de vida infantil; já que compete ao fisioterapeuta conhecer a individualidade de cada criança, bem como a realidade à qual ela está inserida, para uma intervenção que priorize suas necessidades e potencialidades (FUJISAWA, 2002).

Ressalta-se que não devemos tratá-las como adultos em miniaturas, mas como pessoas (CORSARO, 2009) possuidoras de aprendizados inerentes às suas dificuldades, vista como ser potencial capaz de contribuir com sua reabilitação, a qual compreende uma atuação multiprofissional. Ver e ouvi-las nessa perspectiva sugere um tratamento durante a infância mais humanizado, para que este não seja lembrado somente como algo ruim, mas sim como uma conquista diária que lhe possibilita descobrir e usufruir o mundo.

Por que ficar só quantificando-as quando se pode tentar compreendê-las por meio do diálogo, buscando contribuiçôes nos estudos da Sociologia da Infância para investir em pesquisas no campo da fisioterapia que estudem náo somente as crianças e sim com elas?

Quanto a reabilitá-las durante a infância, este estudo acredita que possibilitar o profissional adentrar em seu mundo, compreender o papel da Sociologia da Infância e, principalmente, escutá-las, é uma maneira de proporcionar uma infância de qualidade. Esta pesquisa parte do pressuposto de que é importante que o fisioterapeuta ouça e compreenda o que a criança tem a dizer sobre a fisioterapia. Optando-se por ouvi-las e, sensivelmente, analisando seus pontos de vista, talvez seja possível entender a percepção que elas têm da fisioterapia, levando em consideração sua fase de desenvolvimento tanto intelectual e corporal quanto emocional.

Os fisioterapeutas que atuam em pediatria, e que estão preocupados com a qualidade de vida infantil, precisam compreender que elas não devem ser uniformizadas quanto às suas concepçóes de satisfação pessoal. E sim, que estas são, também, "consumidores", as quais devem ser ouvidas e respeitadas, conforme a sua capacidade de compreensão para seguirem o percurso de suas vidas após descobrirem que são portadores de uma doença crônica. (ARANHA et al., 2000).

Deve-se levar em consideração, portanto, que a criança doente ou deficiente continua sendo criança, e que ela tem de viver a infância. Ela não pode deixar simplesmente de brincar

${ }^{6}$ Devir, segundo Abramowicz e Oliveira (2010), é "aquilo que somos capazes de produzir e de inventar como possibilidade de vida, potência de vida, o poder da vida se opondo ao poder sobre a vida”. 
e de estar em um ambiente caloroso. Sendo assim, profissionais da saúde devem estar atentos à qualidade da relação entre criança e terapeuta, proporcionando um acolhimento digno para a criança de maneira que ela se sinta protegida.

A fim de fazer mais para as crianças, esta pesquisa acredita, que brincar na fisioterapia possa tornar-se mais proveitoso se elas compreenderem e apreciarem o brincar terapêutico. $\mathrm{O}$ motivo de o fisioterapeuta incluir a terapia lúdica à fisioterapia deve-se a esse profissional estar relacionado à necessidade de participação e de motivação da criança para com o tratamento fisioterapêutico, além de que este tipo de terapia facilita o aprendizado (FUJISAWA, 2002). Questiona-se, então, se reabilitar requer pedagogia, pois há uma atuação do fisioterapeuta como educador quando este atua em fisioterapia em pediatria.

Partindo do pressuposto de que as crianças são capazes de falar sobre a fisioterapia, questiona-se: $O$ que dizem as crianças sobre a fisioterapia?

\section{Método}

Esta pesquisa após a aprovação do Comitê de Ética - Parecer: 137/11b, teve sua coleta realizada nos meses de agosto, setembro, outubro e novembro de 2011, em um hospital, e em um centro de fisioterapia do Estado de Santa Catarina, sob o enfoque qualitativo. Participaram desta pesquisa sete crianças, entre as idades de seis e oito anos, com diagnóstico de doença crônica, tais como: Asma (duas crianças), afecçóes crônicas do trato respiratório (doença sob investigação médica), Distrofia Muscular, Mielomeningocele e Paralisia Cerebral (duas crianças), todas realizando fisioterapia por tempo indeterminado.

Todas as crianças que participaram desta pesquisa tiveram o Termo de Consentimento Livre e Esclarecido (TCLE) assinado pelos pais ou responsável no dia da entrevista. As crianças tiverem suas condiçóes clínicas respeitadas, consentiram verbalmente a participação na entrevista e escolheram os nomes fictícios que gostariam de ter no estudo, a saber: Lula Molusco, Maria Cecília, Pucca, Bob Esponja, Isa TKM, Relâmpago e Russel. Foi informado, também, aos responsáveis, que a identidade de seus filhos, bem como suas imagens seriam resguardadas, e que a entrevista trataria de assuntos sobre a fisioterapia e que poderia ser interrompida a qualquer momento.

Durante as entrevistas a pesquisadora fez uso de um roteiro com dezesseis perguntas norteadoras para a análise dos dados, mas que, durante o seu decorrer, foram elaboradas outras perguntas que partiam da resposta anterior das crianças. Essas perguntas partiram de quatro eixos: o significado da fisioterapia, os momentos na fisioterapia, atividades na fisioterapia e objetivos com a fisioterapia.

Para a análise não se utilizou do recurso de categorização, visto que as respostas foram analisadas através de eixos. Optou-se por essa proposta de análise, porque os eixos possibilitam explorar o sentido da opinião coletiva de forma não excludente, categorizada.

As questóes que foram interpretadas ressaltam o que dizem as crianças sobre a fisioterapia, tendo em vista que o objetivo da pesquisa qualitativa é apresentar uma amostra dos pontos de vista dos sujeitos (GASKELL, 2007). Utilizando essa abordagem qualitativa, tendo 
como instrumento de coleta a entrevista, este estudo não quantificou a opinião das crianças, mas sim analisou qualitativamente seus pontos de vista.

A pesquisadora optou por entrevistar crianças que fazem fisioterapia por tempo indeterminado, com doenças crônicas, por estas estarem sob constante estresse, desencadeado pela condição clínica, pela rotina de idas e vindas à fisioterapia e também pelos retornos frequentes ao hospital. Optou-se por pesquisar as crianças no centro de fisioterapia e no hospital porque há nesses locais o atendimento da fisioterapia na área da pediatria.

Quanto às entrevistas no centro de fisioterapia, estas foram realizadas na sala de fisioterapia e na sala de terapia aquática, na presença do pai ou da mãe. No hospital, as entrevistas ocorreram na sua maioria no leito, no entanto, ficava a critério da criança o local onde ela gostaria que ocorresse a entrevista, o que incluía a brinquedoteca.

A escolha do hospital fez-se por ser um hospital universitário onde a pesquisadora, durante a graduação, fez estágio supervisionado, e sabia da existência da internação frequente de crianças por doenças crônicas, geralmente por afecçóes do trato respiratório, que se constituem por recidivas, o que requer mais de uma internação e atendimento da fisioterapia por tempo indeterminado. Esse tipo de doença acarreta desconforto respiratório para as crianças, o que as deixa, muitas vezes, impacientes e intolerantes às condutas da fisioterapia, já que o cansaço e a dispneia podem sugerir dificuldades durante a infância.

O centro de fisioterapia fez parte da pesquisa, por ser um centro onde há crianças com doenças crônicas que realizam fisioterapia também por tempo indeterminado, sendo estas, muitas vezes, possuidoras de algum tipo de deficiência que acarreta dificuldades durante a infância. São doenças comuns de serem atendidas por fisioterapeutas nas clínicas de fisioterapia, bem como nos estágios supervisionados nas instituiçôes de ensino superior. Todos esses aspectos mencionados instigaram a pesquisadora a entrevistar essas crianças, pois a convivência com as dificuldades impostas pela doença e a relação com o fisioterapeuta podem não estar bem compreendidas pelas crianças. A fisioterapia, como parte do cotidiano semanal dessas crianças, despertou interesse na pesquisadora diante à necessidade de conhecimentos pedagógicos sobre a infância, sobre a terapia lúdica e, principalmente, no que diz respeito ao diálogo e à relação adulto e criança.

Os diagnósticos diferenciados possibilitaram a heterogeneidade de participantes. Isso se fez por opção da pesquisadora, que acreditou na riqueza de se investigar o que crianças com diferentes doenças tinham a dizer sobre a fisioterapia - no âmbito da fisioterapia ambulatorial isso foi possível. Porém, no hospital, a pesquisadora teve dificuldades para encontrar participantes, no que diz respeito ao diagnóstico e a faixa etária exigida nesta pesquisa, pois, a maioria das crianças hospitalizadas durante o período da coleta não compreendia, infelizmente, essa faixa etária ou não tinha diagnóstico de uma doença crônica.

\section{Resultados}

Nas entrevistas realizadas, a primeira pergunta feita foi referente ao motivo pelo qual as crianças faziam fisioterapia. Elas deram explicações e demonstraram conhecimento quanto à doença. Isso demonstrou a identificação da criança quanto a esses três pontos mencionados. Isa 
TKM referiu-se à doença em sua complexidade ao dizer: - Por causa do problema do pulmão. (Isa TKM). Assim como fez Pucca: - Eu tenho mielgocele e hidro. Tem uma coisa que colocaram dentro da minha cabeça. (Pucca). Ela quis dizer que tem Mielomeningocele e Hidrocefalia, pois, em uma conversa informal, Pucca falou sobre uma válvula que possui na cabeça devido à doença que chama de hidro.

Todo o conhecimento acerca da doença sugere ser adquirido na trajetória imposta por ela, o que se percebe na fala de Bob Esponja: - Porque... o meu pé né. Quando eu era pequeno, meio né, dai meu pai disse que eu nasci com uma lesão, dai meu pé tá meio torto, dai eu fiz cirurgia, dai ele tá menos torto. (Bob Esponja).

As crianças desta pesquisa não se preocupam com o tempo, com a cronicidade da doença, mas sim pensam em melhorar, e se para melhorar cada vez mais elas precisam fazer fisioterapia por tempo indeterminado, isso parece não ser algo tão preocupante, sendo percebido como uma expectativa pela melhora, para ir de alcance aos seus objetivos, como se pode perceber nesta fala de Maria Cecília: - Porque dai eu tô melhorando cada vez que eu venho mais ainda, eu vou melhorando mais. (Maria Cecília).

Maria Cecília percebe que a fisioterapia “ajuda melhora”. Bob Esponja diz que quer "melhorar mais". Essas crianças demonstram comprometimento com sua saúde e com a fisioterapia, podendo esse comprometimento, talvez, ser mais explorado pelos fisioterapeutas, pois as crianças dizem que querem melhorar e quando percebem o que já melhoraram, demonstram entusiasmo e esperança.

A criança hospitalizada vive em outro contexto, ela torna-se mais sensível e parece sofrer mais, devido às condiçóes que lhe acercam, pois esta pesquisa identificou que as crianças hospitalizadas referem-se à dor e à dificuldade para respirar, dando a entender esse sofrimento, demonstrado nestas falas: - Por que eu canso pra respira. (Relâmpago). - Eu tava com dor e tosse. Aqui atrais, quando eu respirava. (Russel).

As crianças participantes desta pesquisa são otimistas e não pensam em desistir da fisioterapia e querem alcançar a melhora. Lula Molusco fez questão de responder com tamanho entusiasmo sobre essa questão: - [...] com andador eu ando já... até corro com o andador. Maria Cecília diz: - [...] cada vez que eu venho mais, vou melhorando mais, e Bob Esponja: - Ele ficava mais pra dentro, assim (referindo-se ao pé).

Dentre os momentos de declaraçóes surpreendentes, destacou-se aquele em que as crianças se referiram aos seus objetivos para com a fisioterapia, pois quando falavam do porquê de estarem fazendo fisioterapia, percebia-se que seus objetivos derivavam da relação que fazem entre as dificuldades impostas pela doença, suas queixas e seus desejos. Ou seja, o motivo de estarem fazendo fisioterapia descreve as consequências da doença e esclarece seus objetivos, como se percebe nas falas de Maria Cecília e Pucca a seguir cujo objetivo em comum é andar: - pra mim não... encaranga de vez...Anda (Maria Cecília).- Pra anda né máe, pra anda (Pucca).

Bob Esponja quer que o "pé se indireite”. Lula Molusco define seus objetivos: - ai eu comecei a fazer tratamento, pra abrir a perna, não cruza a perna. E acrescenta: - a única coisa que eu quero fazer, que eu não... que eu não consegui até agora é andar sem andador, e correr atrás do meu irmão (Lula Molusco, sorrindo). 
Estariam os fisioterapeutas planejando e intervindo considerando o ponto de vista da criança? Estariam atentos ao que ela também almeja naquele momento, considerando a infância? O fisioterapeuta, quando atento à percepção de melhora referida pelo paciente pediátrico, pode usar dessa observação para elucidação de dúvidas quanto às condutas realizadas.

O fisioterapeuta que utiliza a terapia lúdica no hospital está mais propício ao vínculo, o que pode ser percebido na fala de Relâmpago (o qual estava hospitalizado), pois, quando questionado se gosta de fazer fisioterapia, respondeu: - Sim. Eles fazem coisa pra eu ri.

Isso faz compreender o quanto à fisioterapia em que a criança sorri e brinca parece ser importante para a relação entre fisioterapeuta e paciente no hospital, já que, nesse local, é mais difícil de obter-se vínculo com a criança, pois vincular-se requer maior contato, mais tempo com ela, o que é complicado nesse ambiente, porque a demanda de atendimentos requer uma rotatividade maior desse profissional, e o tempo que ele tem com o paciente, muitas vezes, compreende o tempo da terapia.

Se as crianças compreendem a importância do tratamento, por que não as emponderar mais? Por que não solicitar mais sua participação e comprometimento com a terapia, ou seja, consigo mesmas? Pois elas relatam que a fisioterapia ajuda a melhorar, o que se percebe nas falas de Bob Esponja e Maria Cecília: - Lógico, se não vô piorando (Bob Esponja). - Sim. Porque na fisioterapia isso ajuda melhora (Maria Cecília). Pode-se observar que a maioria dessas crianças relaciona a importância da fisioterapia, porque almejam a melhora, ou já a percebem.

Por meio de suas falas, pode-se identificar que há uma rotina nas sessóes de fisioterapia, mas esta não precisa ser entediante. Bob Esponja diz: - [...] é mais ou menos, porque tem vezes, assim, no começo era legal né. Mas dai foi enchendo o saco (sorrindo).

A criança não deveria perder o interesse pelo tratamento, e sim ser motivada constantemente. Pois é provável que a criança necessite de que a fisioterapia seja composta de novidades e não somente de uma rotina pouco criativa.

Quando as crianças referiram-se às dificuldades impostas pela doença, não se referiram somente no âmbito da doença e da fisioterapia, com liberdade, elas expuseram as dificuldades e argumentaram sobre a vida lá fora, na qual elas são também alunos, como Maria Cecília fez ao dizer que "Tem algumas meninas que querem jogar bola". Bob esponja também traduz sua dificuldade no âmbito escolar: - Só na educação física lá que tem uns guri* maluco, que ficam que nem notam que eles tão correndo, e dai "bum" (se referiu aos meninos colidirem com ele).

Isso remete uma atenção maior que a escola deveria ter quanto a estas dificuldades elencadas por estas crianças, pois isso sugere monitoramento da escola e da família. Além disso, reforça a importância da atuação do fisioterapeuta nas escolas, já que a criança demonstra medo de cair e restrição ao brincar. O fisioterapeuta pode atuar na escola, intervindo no espaço físico, promovendo melhores condições para a criança brincar, como, por exemplo, melhorar seu controle de tronco, o que remete a uma perspectiva de inclusão.

Identificou-se que a criança deseja brincar na fisioterapia e está em busca de melhores condiçóes físicas para brincar. $\mathrm{Na}$ maioria das vezes, as brincadeiras na fisioterapia apareceram relacionadas com as condutas fisioterapêuticas, porém, para as crianças, a brincadeira acontece 
só no final da sessão, o que se observa na fala a seguir: - no final eu tenho uma brincadeira, [...] é tem o momento que dá pra brincar né (Lula Molusco, referindo-se que brinca na hidroterapia em alguns momentos, e não associa esse momento com a fisioterapia).

No hospital, não há o momento distinto de brincar, mas a maneira lúdica adotada por Relâmpago e pelo fisioterapeuta, em transformar o oscilador oral de alta frequência em cachimbo do Popeye, fez com que Relâmpago não percebesse a intervenção fisioterapêutica como algo ruim, e sim a viu como brincadeira, e interagiu, pois o aparelho tornou-se um recurso lúdico e facilitou a terapia. Após a entrevista, ao conversar um pouco mais sobre o cachimbo do Popeye, Relâmpago revelou que partiu dele a ideia da brincadeira. Percebe-se, então, que o fisioterapeuta acatou prontamente sua ideia, e, a partir da exploração imaginária do aparelho de higiene brônquica fazendo parte da terapia lúdica, ocorre o brincar terapêutico.

Lula Molusco fala sobre os exercícios que faz na hidroterapia os quais, para ele, são o momento de brincar: - Tipo assim, a gente, (referiu-se ao fisioterapeuta) me bota numa boia, numa boia assim a gente vai pedalando, eu tenho que... que pega (referiu-se ao fisioterapeuta) com golpe de ... caratê (sorrindo constantemente enquanto falava). Só a única fisioterapia que eu faço que eu não brinco é a fisio né. Grupinho, é que o grupinho, é... a gente brinca de um monte de coisa lá no grupinho (Lula Molusco, sorrindo).

Nesse momento, Lula Molusco quer dizer que brinca só na hidroterapia, mas não associa que ao pedalar para pegar o fisioterapeuta com golpe de caratê está brincando e ao mesmo tempo fazendo exercício. Assim, a fisioterapia torna-se mais prazerosa e gera recordaçóes, pois ela parte da brincadeira e o exercício vem associado inconscientemente. Essas recordações também podem ser aproveitadas nas sessóes posteriores para continuidade daquela etapa já atingida durante aquelas brincadeiras vinculadas ao exercício. Acredita-se ser mais fácil para a criança lembrar-se da brincadeira que fez na sessão anterior a lembrar do exercício propriamente.

Isa TKM diz que "brincar em casa é diferente”, mas gostaria de brincar no hospital: - é chato sem fazer nada. Relâmpago complementa: - Mais diferente. Aqui não tem também amigo. Sinto saudade da bicicleta, eu ando com a bicicleta grande do vô. (Relâmpago).

Estariam as falas das crianças sugerindo que elas querem participar integralmente das atividades realizadas na fisioterapia? Incluir mais a brincadeira poderia ser uma maneira de fazer emergir essa ótica mais integral da criança? Por este viés, estes questionamentos suscitam cada vez mais que reabilitar requer pedagogia e reforço.

\section{Discussáo}

Segundo Araújo et al. (2010, p. 427): “A formulação de questões veiculadas à doença permite a compreensão das significaçôes que a criança atribui a essa vivência”, portanto o entendimento da doença faz-se de acordo com a capacidade de compreensão da criança em relação ao tempo que está doente e/ou deficiente, e o quanto de conhecimento prévio ela tem a respeito, sendo este advindo de explicaçôes dadas pelos pais ou pela equipe multiprofissional, podendo ser fruto de recordaçóes de conversas entre adultos. 
As falas das crianças precisam ser norteadoras das ações de cuidados, bem como de novas estratégias a serem utilizadas pelos profissionais (ARAÚJO et al., 2010). Schmitt (2011) considera a necessidade de incluir o significado social que cada um ocupa em determinado contexto, sendo de suma importância compreender, também, em que espaço e tempo a criança encontra-se com suas determinaçóes, suas açóes e suas iniciativas nessa relação profissional e paciente.

Fujisawa (2003, p. 106) afirma que: "A formação do vínculo da criança com o adulto é facilitada por meio dos jogos e das brincadeiras, porém essa interação ocorre de forma gradativa”. A falta de interação entre o fisioterapeuta e a criança pode levar a falta de colaboração ou do consentimento desta na realização das condutas fisioterapêuticas. (FUJISAWA; MANZINI, 2010).

Quando a criança está envolvida, ela percebe que seus pontos de vista estão sendo valorizados, sente-se respeitada e segura, podendo colaborar para torná-la mais engajada nessa batalha, e, assim, ela passa a cultivar a esperança e a vontade de melhorar, aderindo mais ao tratamento. Ela pode vir a perceber que, se está envolvida e compreende o que acontece com sua saúde, possui certo controle da situação a qual lhe diz respeito, e poderia, quem sabe, policiar-se quanto a suas reações e justificar suas negações.

A hospitalização é uma situação geradora de estresse, não somente devido ao tratamento, mas também pensando no ambiente ao qual se está inserido, que é restritivo e diferente de seu universo habitual. As atividades lúdicas têm demonstrado cientificamente seus benefícios físicos e emocionais, favorecendo o tratamento de crianças hospitalizadas, pois o brincar, além de trazer alegria, tem demonstrado ser um instrumento facilitador do tratamento. (MUSSA; MALERBI, 2008). Nessa perspectiva, o fisioterapeuta que utiliza a terapia lúdica no hospital, está mais propício ao vínculo. Pequenas atitudes que divertem, e que ao mesmo tempo dialogam, propiciam uma interação maior das crianças durante a fisioterapia, e humanizam o atendimento mesmo que o vínculo não esteja bem estabelecido.

O acolhimento, a empatia, o diálogo e as brincadeiras podem fazer toda a diferença, o que se evidenciou nesta pesquisa. As crianças destacaram esses momentos de contato e de brincadeiras, momentos que percebem o fisioterapeuta como um parceiro e a fisioterapia como uma aliada para sua melhora. Isso sugere que os momentos agradáveis, que geram boas recordaçóes, sobressaem-se aos momentos que reforçam aspectos negativos, dentre eles: a hospitalização, a rotina imposta pela doença, as condutas fisioterapêuticas e os exercícios os quais não são muito agradáveis no ponto de vista da criança -, a dor, o cansaço, dentre outras dificuldades. Isso suscita refletir sobre como conduzir uma prática pedagógica na sociedade contemporânea, que venha priorizar a "formação de sujeitos para o desenvolvimento autônomo, aberto e criativo" (GESSER; RANGHETTI, 2011b, p. 114) para que se supere a visão fragmentada e se propague uma educação integral e integradora de conhecimentos.

Com a ampliação do campo de atuação, a Fisioterapia vive o crescimento acelerado de cursos de graduação, e, com isso, tem-se o aumento de profissionais que não tiveram as vivências necessárias nessa abordagem mais ampliada de saúde, a qual exige um perfil mais humanista que tem como perspectiva melhorar a qualidade de vida das pessoas. (BAENA; SOARES, 2011). 
O fisioterapeuta, quando é visto como um parceiro pela criança, faz com que ela goste da terapia, e assim ele estaria humanizando essa relação. Quando há a terapia lúdica associada à sessão, esta é bem quista, mesmo não sendo possível o fisioterapeuta brincar durante toda sessão, pois a criança reconhece o momento que brinca e passa a ter expectativas para as outras sessóes. Lembrando que terapia lúdica deve estar sempre vinculada aos objetivos estabelecidos, sendo este um recurso e atividade-meio. A atividade lúdica explorada na fisioterapia difere-se do brincar livre, pois demanda que ela esteja em consonância com os objetivos fisioterapêuticos. (FUJISAWA; MANZINI, 2010).

No entanto, durante a fisioterapia, o profissional poderia utilizar-se mais do brincar terapêutico, e a criança talvez passasse a corresponder mais à terapia. Pensa-se que os exercícios possam trazer a fantasia e explorar mais a imaginação da criança, mas, para isso, precisa-se refletir sobre a origem da escolha do repertório lúdico, sendo necessário planejamento e continuidade dessa atividade, para que não ocorra, talvez, só em momentos distintos como destaca esta pesquisa. A terapia lúdica poderia ter um alicerce teórico anterior à prática, partindo dos conhecimentos prévios dos acadêmicos, porém de uma maneira autônoma, mas com base em conhecimento teórico que abordasse os aspectos da infância, para, então, apropriarem-se com propriedade desse tipo de atividade e, assim, melhor conduzi-la.

Enumo e Motta (2004, p. 25-26) falam que o interesse e o uso da brincadeira no hospital devem-se, principalmente, ao "efeito imediato que têm ao se divertir e se entreter". A criança, porém, consegue esse efeito se o hospital fornecer-lhe recurso para o brincar. Pode-se pensar, também, que se a equipe profissional propicia a socialização entre as crianças, elas, além de brincarem, poderiam trocar experiências referentes à hospitalização e à doença, vivenciando, assim, momentos com seus pares.

Braccialli, Manzini e Reganhan (2004) apontam que, ao brincar, a criança é estimulada, desenvolve-se e aperfeiçoa aspectos indispensáveis como a memorização, a concentração, a motivação, a motricidade, a socialização, adquirindo confiança em si e nas suas possibilidades, ou seja, o mesmo que se objetiva com os exercícios fisioterapêuticos, só que estes, muitas vezes, tornam a fisioterapia repetitiva, entediante, sem graça, e, assim, a criança vai desmotivando-se do tratamento, ao contrário do brincar, que a torna mais entusiasmada.

É preciso ter em mente que, mesmo estando doente e hospitalizada, a criança possui a necessidade de brincar, e é por meio das brincadeiras que ela pode comunicar seus medos, suas angústias, seus afetos e suas alegrias. (LIMA; VIEIRA, 2002).

Araújo et al., em seu estudo quanto à percepção das crianças em adaptarem-se para brincar, identificam que:

Elas [as crianças] entendem não poder realizar atividades que gostam, ou que consideram comuns a todas as crianças e acabam tendo que procurar outras opçóes que até contribuem para a diversão, mas parece não ser o que realmente gostariam de fazer. Essas crianças buscam mecanismos de adaptação de modo a melhorar a qualidade de vida. (ARAÚJO et al., 2010, p. 431).

As brincadeiras no ambiente hospitalar, advindas da interação da criança com a equipe que compóem o corpo clínico, por intermédio de recursos lúdicos, promove melhor evolução clínica da criança, diminuem o estresse causado pela hospitalização e favorecem a aceitação de 
procedimentos clínicos realizados (AZEVEDO et al., 2008). O brincar e o brinquedo, em uma enfermaria pediátrica, revestem a terapêutica. (CHAVES; MOTA, 2009). Os profissionais de saúde e cuidadores devem escutar atentamente, acreditar e considerar as queixas relatadas pelas crianças em relação à sua saúde, para que essas queixas sejam norteadoras das açóes de cuidados, tanto no hospital quanto no domicílio (ARAÚJO et al., 2010).

Humanizar as relações sociais com a criança é propiciar melhor relação paciente e fisioterapeuta, sendo necessário compreender que a conduta fisioterapêutica deve propiciar o vínculo, o acolhimento e não excluir o paciente. A humanização tem como objetivo que os profissionais atuem sobre as relaçóes eliminando a subjetividade (JEOLÁS; SUMIYA, 2010). Conforme Gesser e Ranghetti (2011a), “[...] as políticas curriculares, especialmente no ensino superior, bem [como] os princípios para um design de currículo que atenda a essas novas demandas sociais, humanas e profissionais carecem de novas escolhas".

Refletir, portanto, sobre os estágios supervisionados nessa abordagem mais humanizada, que conversa mais com a criança, é importante, pois pensar no currículo do curso de fisioterapia parece ser uma maneira para engajar-se nessa perspectiva que visa um olhar sob a ótica da integralidade, a qual compreende que proporcionar qualidade de vida para a criança vai além dos cuidados com sua saúde.

\section{Conclusão}

Como pessoas singulares, as crianças demonstraram conhecimento acerca da fisioterapia e falaram de suas dificuldades nas sessões, entre estas destacaram alguns exercícios, o fato de fazer força, empurrar, tossir, dor e cansaço. Sobre a escola, elas falaram da dificuldade em jogar bola, citando a educação física.

Além de perceberem a melhora, elas descreveram o que já haviam melhorado e enfatizaram que poderiam piorar se não fizessem fisioterapia. Assim, as crianças compreendem que quanto mais frequentarem a fisioterapia, mais irão melhorar, sendo a melhora o objetivo que elas mais almejam. Acredita-se, porém, na necessidade de uma maior participação e de interação da criança durante a fisioterapia, pois não é só a frequência em si das sessões que se traduz na melhora, mas sim a intensidade que compreende um atendimento humanizado, que respeite a infância e o brincar.

Sendo assim, o instrumento lúdico não deveria ser usado como uma forma de subordinação, pois este tem grande valia - ele compreende a infância e pode talvez proporcionar qualidade de vida infantil e humanizar a fisioterapia. Quando administrada de forma respeitosa e adequada, a terapia lúdica pode ser conduzida a um brincar terapêutico, e assim percebida pelas crianças.

Elas dizem que fazem fisioterapia para melhorar, pois estão em busca de mais independência, interação com o mundo e seus pares, querem respirar melhor e poderem ir para casa, brincar, ir à escola, ou seja, querem viver a infância como e/ou com as crianças, e isso mostra que elas querem qualidade de vida infantil. Demonstram que o incentivo é fundamental, e que a família e a fisioterapia são suas aliadas. As crianças que se sentem acolhidas vinculam-se e aderem à fisioterapia como algo indispensável, que dão tamanha importância. 
As crianças observam e sabem o que fazem na fisioterapia e por que fazem. Mostraramse capazes de elucidar alguns pontos de vista que venham a contribuir para elucidação de como tornar as sessóes mais interessantes para elas. Elas sugerem que a fisioterapia na sala de fisioterapia poderia ser como na hidroterapia, onde brincam, interagem com seus pares e, provavelmente, esquecem-se da doença e das suas limitaçóes.

As crianças relacionam o brincar no hospital com a fisioterapia no momento que trazem o lúdico advindo de sua imaginação. Talvez o fisioterapeuta pudesse explorar mais o repertório lúdico nesse ambiente, independentemente de partir dele ou da criança a brincadeira.

Por meio dessa pesquisa, pode-se observar que as crianças participantes ressaltaram que não brincam na sala de fisioterapia, pois lá é lugar para fazer exercícios, mas que também tem o momento de brincar, sendo a terapia lúdica pouco explorada. Percebe-se que é durante a fisioterapia aquática que os exercícios são mais associados ao lúdico, sendo estes os mais lembrados em detalhes com certo entusiasmo, vistos como brincadeira e não como exercício - é o momento de brincar na hidroterapia que faz a terapia ser apreciada por submeter a criança ao prazer que a brincadeira proporciona.

Quando se ouve as crianças, está-se despindo de pré-conceitos e passa-se a observálas dentro de uma perspectiva de integralidade, como pessoas que constituem a sociedade e que possuem opinióes. O que elas têm a dizer pode subsidiar mudanças e proporcionar qualidade de vida infantil, e pode trazer mudanças significativas para a fisioterapia pediátrica, como encaminhá-la para uma relação humanizada em que a criança acredite cada vez mais na fisioterapia e no que esta pode proporcionar-lhe.

Buscar ter em si as palavras e o olhar crítico das crianças sobre ou a respeito da fisioterapia, possibilitou descobrir que os fisioterapeutas e o Curso de Graduação em Fisioterapia necessitam refletir no campo teórico e prático a respeito da infância, ouvindo o que as crianças têm a dizer. Para que assim se possa melhorar a qualidade de vida infantil, tendo como premissa o diálogo, o qual possibilita também uma relação de amizade, respeito, empatia entre criança e fisioterapeuta.

\section{REFERÊNCIAS}

ABRAMOWICZ, A; OLIVEIRA, F. A Sociologia da Infância no Brasil: uma área em construção. Revista Educação, Santa Maria, v. 35, n. 1, p. 39-52, jan./abr. 2010. Disponível em: <http://www.ufsm. br/revistaeducacao $>$. Acesso em: 4 nov. 2011.

ARANHA, E. M. G. et al. Escala de Avaliação de Qualidade de Vida. Arquivos de Neuro - Psiquiatria [online], v. 58, n. 1, p. 119-127, 2000. Disponível em: <http://www.scielo.br/pdf/anp/v58n1/1267. pdf>. Acesso em: 5 jul. 2011.

ARAÚJO, Y. B. et al. Criança em idade escolar hospitalizada: significado da condição crônica. Revista Texto e Contexto de Enfermagem [online], v. 19, n. 3, p. 425-433, 2010. Disponível em: <http://www. scielo.br/pdf/tce/v19n3/a03v19n3.pdf>. Acesso em: 28 fev. 2011. 
AZEVEDO, D. M. et al. O brincar enquanto instrumento terapêutico: opinião dos acompanhantes. Revista Eletrônica de Enfermagem [online], v. 10, n. 1, p. 137-144, 2008. Disponível em: <http://www. fen.ufg.br/revista/v10/n1/v10n1a13.htm>. Acesso em: 6 nov. 2011.

BAENA, C. P; SOARES, M. C. F. Fisioterapia e integralidade: novos conceitos, novas práticas. Estamos prontos? Revista Fisioterapia Brasil [impresso], v. 12, n. 2, p. 133-138. mar./abril, 2011.

BRACCIALLI, L. P.; MANZINI, E. J.; REGANHAN, W. G. Contribuição de um programa de jogos e brincadeiras adaptados para a estimulação de habilidades motoras em alunos com deficiência física. In: ANPED: Vigotski Brasil: Links em psicologia histórico-cultural. 2004. Disponível em: <http:// www.anped.org.br/reunioes/27/gt15/t154.pdf>. Acesso em: 4 nov. 2011.

BURLEY, S. C; DAVIS, J.; WATSON, N. Aprendendo as vidas de crianças com deficiência. In: CHRISTENSEN, P.; JAMES, A. (Org.). Investigação com crianças: perspectivas e práticas. Porto: Ediliber, 2005.

CHAVES, P.; MOTA, M. C. Brinquedoteca Hospitalar "Nosso Cantinho". In: SALLES, F.; GUINARAES, M.; DEBORTOLI, J. A. (Org.). Brincar(es). Belo Horizonte: UFMG, 2009.

CORSARO, W. A. Métodos etnográficos no estudo da cultura de pares e das transiçôes iniciais na vida das crianças. In: MÜLLER, F.; CARVALHO, A. M. A. (Org.). Teoria e Prática na pesquisa com crianças: Diálogos com William Corsaro. São Paulo: Cortez, 2009.

ENUMO, S. R. F.; MOTTA, A. B. Brincar no hospital: estratégia de enfrentamento da hospitalização infantil. Revista Psicologia em Estudo [online], v. 9, n. 1, p. 19-28, jul./set. 2004. Disponível em: <http://www.scielo.br/pdf/ptp/v26n3/a07v26n3.pdf>. Acesso em: 3 nov. 2011.

FUJISAWA, D. S. Atendimento fisioterapêutico de crianças: uma análise na perspectiva da teoria histórico-cultural. Revista Temas sobre Desenvolvimento [impresso], v. 11, n. 63, p. 37-44. 2002.

. Formação Acadêmica do Fisioterapeuta: a utilização de jogos e brincadeiras nos atendimentos de crianças. 2003. 162 f. Tese (Doutorado em Educação) - Faculdade de Filosofia e Ciências, Campus de Marília, Universidade Estadual Paulista. Marília, 2003.

FUJISAWA, D. S.; MANZINI, E. J. O jogo e a brincadeira no atendimento de crianças: brincar ou um recurso na fisioterapia? In: . (Org.). Jogos e Recurso para Comunicação e Ensino na Educação Especial. Marília: Abpee, 2010.

GASKELL, G. Entrevista Individuais e Grupais. In: BAUER, M. W.; GASKELL, G. (Org). Pesquisa qualitativa com texto, imagem e som: um manual prático. Petrópolis: Vozes, 2007.

GESSER, V.; RANGHETTI, D. S. O currículo no ensino superior: princípios epistemológicos para um design contemporâneo. Revista e-curriculum [online], v. 7, n. 2, p. 1-23, Ago. 2011a. Disponível em: <http://revistas.pucsp.br/index.php/curriculum/article/view/6775/4902>. Acesso em: 1 dez. 2011.

GESSER, V.; RANGHETTI, D. S. Currículo Escolar. Das concepçôes histórico-epistemológicas a sua materialização na prática dos contextos escolares. Curitiba: CRV, 2011 b.

JEOLÁS, L. S.; SUMIYA, A. Processos de mudança na formação do fisioterapeuta: as transiçóes curriculares e seus desafios. Acta Scientiarum. Human and Social Sciences, [online], v. 32, n. 1, p. 47-53, 2010. Disponível em: <http://periodicos.uem.br/ojs/index.php/ActaSciHumanSocSci/article/ view/4107/p4107df>. Acesso em: 19 maio 2011.

LIMA, R. A. G.; VIEIRA, M. A. Crianças e adolescentes com doença crônica: convivendo com mudanças. Revista Latino-Americana de Enfermagem, [online], v. 10, n. 4, p. 552-560, jul./ago. 2002. Disponível em: <http://www.scielo.br/pdf/rlae/v10n4/13368.pdf>. Acesso em: 7 julho 2011. 
MUSSA, C.; MALERBI, F. E. K. O impacto da atividade lúdica sobre o bem estar de crianças hospitalizadas. Revista Psicologia: Teoria e Prática, [online], v. 10, n. 2, p. 83-93, 2008. Disponível em: <http://www.revistasusp.sibi.usp.br/pdf/rbcdh/v18n3/03.pdf>. Acesso em: 21 set. 2011.

SARMENTO, M. J. Geraçôes e alteridade: interrogaçóes a partir da sociologia da infância. Revista Educação e Sociedade, [online], v. 26, n. 91, p. 361-378, maio/ago.2005. Disponível em: <http://www. scielo.br/pdf/es/v26n91/a03v2691.pdf>. Acesso em: 25 set. 2011.

J. Sociologia da Infância: Correntes e Confluências. In: GOUVEA, M. C.S.; SARMENTO, M. J. (Org.). Estudos da Infância. Educação e Práticas sociais. Rio de Janeiro: Vozes, 2009.

Recebido em: 13/07/2012

Reformulado em: 17/04/2013

Aprovado em: 20/05/2013 